\title{
The Phonetics and Phonology of Unreleased Stops in Karitiana
}

\author{
LUCIANA STORTO ${ }^{\mathrm{i}}$ and DIDIER DEMOLIN ${ }^{\mathrm{ii}}$ \\ ${ }^{\mathrm{i}}$ Museu de Arqueologia e Etnologia/Universidade de São Paulo and Phonology \\ ${ }^{i i}$ Laboratory, Université Libre de Bruxelles
}

\section{Introduction}

Karitiana, an endangered language from the Tupi stock, Arikem family, spoken in the state of Rondonia in Brazil, exhibits a number of interesting phenomena concerning stop consonants at the end of words. In particular, voiceless stops are always unreleased word-finally. This phenomenon has been observed as an occasional variant of stops in English (Laver 1994, Ladefoged \& Maddieson 1996) and in a number of other languages such as Bamileke (Westermann \& Ward 1952) and Efik (Cook 1969), and is systematic in Karitiana. Unreleased final stops are also common in Tupi languages and have been described by several researchers (e.g. Moore 1984; Galucio 1994, 1996; Gabas Jr. 1998, 1999; Picanço 1999; Storto 1999; Rose 2000). Such facts have rarely been described in a detailed manner. This paper describes some phonetic and phonological aspects of the nature of these sounds when they appear word finally. More specifically, three points will be examined: (i) voiceless stop consonants (there are no phonemic voiced consonants in Karitiana); (ii) nasal consonants, which have been described as unreleased word finally by Storto (1999), and (iii) the phonological behavior of these consonants in context.

\section{The Phonetics of Word Final Stop Consonants}

\subsection{Materials}

Data were collected in Brazil with 4 male subjects. Measurements were made to record acoustic, aerodynamic and articulatory data. All subjects contributed to all of the different modes of recording and measurement. Acoustic recordings were made with a Shure headset microphone, which enables the maintenance of a constant distance between the subject's lips and the microphone. This method allows data to be recorded in a way which is both comfortable for the speaker and prevents amplitude variations due to head movement during recording. Acoustic and aerodynamic data were recorded with a portable MacQuirer workstation and have been processed with the Signal Explorer and Formants software. The recordings were digitized at $20 \mathrm{kHz}$. Video data were recorded with a Sony DV 
camera which captures images and acoustic data simultaneously. Finally, palatograms and linguograms were made using stimuli containing intervocalic and word-final alveolar nasals. Data are based on Storto's 1999 description of Karitiana phonology. The stimuli used for the experiments are shown in (1) and (2) below.

(1) Karitiana words used for the acoustic and aerodynamic recordings

\begin{tabular}{|c|c|c|c|}
\hline Stops & & Nasals & \\
\hline$\overline{\text { gep }}$ & 'lice’ & $\overline{\text { ฤãm? }}$ & 'rotten' \\
\hline gop? & 'wasp' & nõm’ & 'breasts' \\
\hline gip? & 'termite' & mãm? & 'to tighten' \\
\hline Pot' & 'to fall' & mãn' & 'husband' \\
\hline ?it $^{\top}$ & 'son' (father speaking) & põn' & 'to play' \\
\hline Pet' & 'son' (mother speaking) & pasẽn' & 'cricket' \\
\hline ãndik' & 'buttocks' & sõy’ & 'firewood' \\
\hline $\mathrm{t} \int \mathrm{ak}^{\urcorner}$ & 'to bite' & $\tilde{\sin }{ }^{7}$ & 'to grind' \\
\hline apibmbik' & 'to push' & ãmãy & 'to plant' \\
\hline põm? & 'to play' & pat ${ }^{2}$ & 'macaw' \\
\hline kat ${ }^{\top}$ & 'to sleep' & õmp? & 'tadpole' \\
\hline
\end{tabular}

(2) Karitiana words used for the articulatory recordings

\begin{tabular}{llll}
\multicolumn{2}{l}{ Palato/linguogram } & Video & \\
\hline pat' & 'macaw' & mẽm' & 'to enter' \\
ota & 'friend' & sõm' & 'red' \\
mãn' & 'husband' & opo & 'penis' \\
õñ & 'that' & sop' & 'hair'
\end{tabular}

\subsection{Methods}

Acoustic data were recorded in two sessions: the first time separately from the aerodynamic measurements, the second time in tandem with those measurements. In each recording session, subjects were asked to repeat each of the words in (1) multiple times: once in isolation and three times in a short carrier sentence, Karitiana haadna pip $X$ nakaat $Y$ 'In Karitiana $X$ is $Y$ ' (where $Y$ is the gloss of $X$ in Portuguese). Length measurements were made on the audio waveform using a spectrogram. The duration of inter-vocalic nasals was measured starting from the last cycle of the preceding vowel to the first cycle of the following vowel. When in initial position, this was done from the first observable cycle of voicing to the first cycle of the following vowel. The duration of final nasals was measured starting from the last cycle of the preceding vowel to the last observable cycle.

The aerodynamic data consist of pharyngeal pressure, nasal airflow, and oral airflow measurements. Oral airflow measurements were taken with a small flexible silicone mask placed against the mouth. Nasal airflow was measured with a nasal mask set around the nose. Pharyngeal pressure was recorded with a small 
flexible plastic tube (ID $2 \mathrm{~mm}$ ) inserted through the nasal cavity into the oropharynx for one subject. One session involved the recording of acoustic and aerodynamic parameters simultaneously and another session recorded only oral and nasal airflow. In both cases, the microphone was placed next to the mask used to record oral airflow.

As the three other subjects did not tolerate the tube used to make pharyngeal pressure measurements, pressure measurements were only made for labial consonants with those subjects. This was done by asking the subjects to hold a plastic tube (ID $5 \mathrm{~mm}$ ) between the lips.

Articulatory data were also collected in two different sessions. The first involved simultaneous recording of face and profile images using a digital video camera. Profile images were obtained by putting a mirror against the cheek of the speaker, at a $45^{\circ}$ angle to the sagittal plane. These data were intended to study the relative timing of lip movements during the realization of the sounds [ $\left.\mathrm{m}^{\top}, \mathrm{n}^{\mathrm{\gamma}}, \mathrm{g}^{\top}\right]$. The camera was used in order to allow for comparisons to be made with non-final (released) nasals. The audio signal was recorded simultaneously by the camera. The second session involved the use of the "classical" method for making palatograms and linguograms (Dart 1991). Subjects were asked to pronounce a word containing the consonant under study after their tongues or palates had been painted with an equal mixture of charcoal and olive oil. In the case of palatograms, a mirror was then inserted into the mouth and the print on the hard palate was photographed with the video camera. For linguograms, subjects were asked to pronounce a word after their hard palates were painted with the charcoal/olive mixture. The print on the tongue was then photographed with a video camera.

\section{Results \\ 2.1 Acoustics}

\subsubsection{Stops}

Results from the acoustic measurements, presented in (3a-d) show that formant transitions always identify the place of articulation of the consonant. Analysis of the corresponding audio waveform shows that these consonants are indeed stops with no bursts. There is no burst at the end of the spectrogram of [kat'] 'to sleep' in (3a). Starting from the velar transition, there is a lowering movement of F2 towards the locus of the alveolar consonant and a rising movement of $\mathrm{F} 3$ towards the locus estimate $(2500-2700 \mathrm{~Hz})$. Figure (3b) shows that when no consonant follows the final vowel [a], there are no observable formant transitions. Formant transitions at the end of the spectrogram of [gep'] 'lice' in (3c) show a lowering of $\mathrm{F} 2$ and $\mathrm{F} 3$ towards their loci estimates $(1100-1500 \mathrm{~Hz})$ and $(2200-2400 \mathrm{~Hz})$. Formant transitions at the end of the word [ãndi:k'] 'cold' in (3d) show the convergence of $F 2$ and $F 3$, as expected for velar stops. 
(3) Spectrograms and waveforms of [kat'] 'to sleep', [ota] 'friend', [gep'] 'lice', and [ãndi:k'] 'cold'
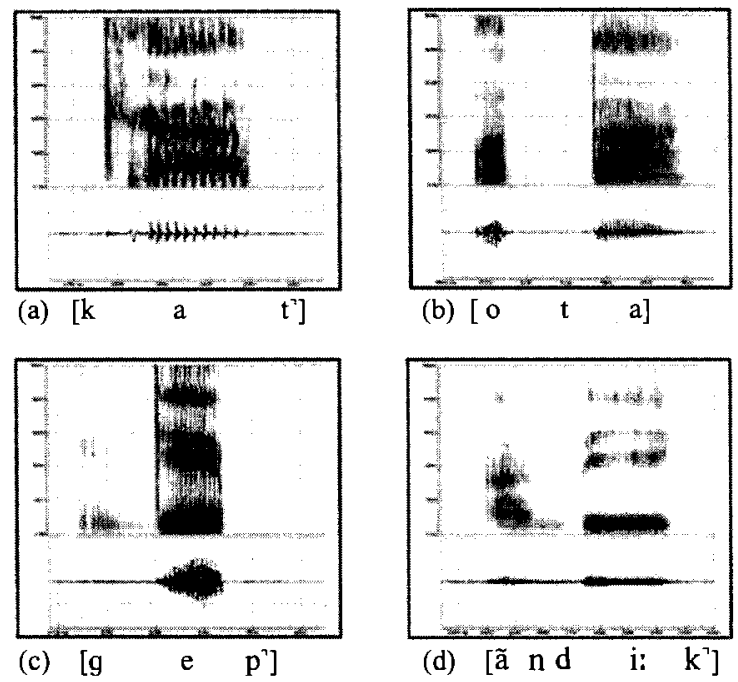

\subsubsection{Nasals}

Acoustically, the main feature differentiating a non-final nasal, which is in fact a post-stopped nasal (see Storto \& Demolin (2002) for details on post-stopped nasals), from an unreleased final nasal is duration. (Post-stopped nasals are transcribed as $\left[\mathrm{m}^{\mathrm{b}}, \mathrm{n}^{\mathrm{d}}, \mathrm{\eta}^{\mathrm{g}}\right]$.) Table (4) shows that the average duration of unreleased final nasals is greater when compared to the non-final nasals.

(4) Average duration in ms of non-final nasals and of final unreleased nasals ( $\mathrm{n}=54$ for each speaker).

\begin{tabular}{|c|c|c|c|}
\hline Non-final nasals & $\underline{\mathrm{ms}}$ & Final unreleased & $\underline{\mathrm{ms}}$ \\
\hline $\mathrm{m}^{\mathrm{b}}$ & $\overline{191}$ & $\mathrm{~m}^{\prime}$ & $\overline{221}$ \\
\hline$n^{d}$ & 172 & $\mathrm{n}^{\top}$ & 255 \\
\hline $\mathrm{y}^{\mathrm{g}}$ & 120 & $y^{\prime \prime}$ & 176 \\
\hline
\end{tabular}

\subsection{Aerodynamics}

\subsubsection{Stops}

Results of aerodynamic measures show that when the closure is maintained until well after the word, as for an unreleased stop, pharyngeal pressure dissipates gradually. Sometimes an increase in nasal flow can be observed at the beginning of the final consonant, as can be seen in (5). 
(5) Spectrogram, waveform, pharyngeal pressure and nasal airflow for [õmp'] 'tadpole'

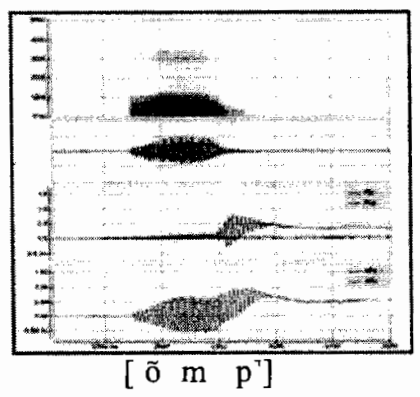

When an unreleased stop is followed by a word starting with a voiceless stop consonant in a compound form or in a sentence, a burst is produced because pressure is released sharply. Sometimes, but much less frequently, the unreleased stop assimilates completely to the following stop without any observable drop in pressure (see Sections 3.1 and 3.2 for more details on this phenomenon). In context, a clear drop in pharyngeal pressure can sometimes be observed between two consecutive voiceless stops, the first being the final consonant of a word and the second the initial consonant of the following word. This drop in pressure accounts for the observed burst, but it should be noted that it marks a pause between two words and not a complex consonant cluster.

\subsubsection{Nasals}

It can be observed in (6) that an increase in nasal airflow starts when the oral airflow stops. Note that nasal airflow is maintained well after the nasal voicing ceases. The maintenance of nasal airflow and also of lip closure accounts for the unreleased nature of these nasals, which differ from post-stopped nasals that are realized with a clear burst when the lip closure is released (see Storto \& Demolin (2002) for a detailed description of post-stopped nasals).

(6) Spectrogram, waveform, pharyngeal pressure, and nasal airflow for [põm'] 'to play'

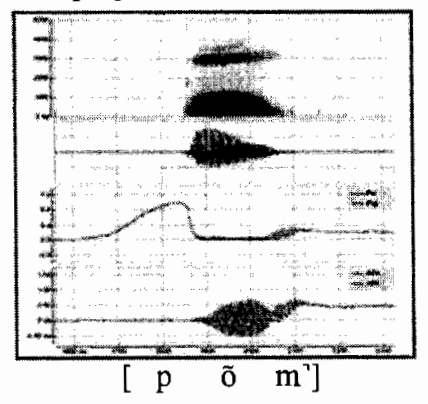




\subsection{Articulatory Data}

\subsubsection{Palatograms and Linguograms}

The main observations that can be made from the palatograms and linguograms realized with the speakers of this study is that when a stop is unreleased word finally it has a wider tongue contact compared to the same stop in intervocalic or initial positions. This can be seen in (7), which shows palatograms and linguograms of the words [pat'] 'macaw' and [ota] 'friend' for one of the speakers. In addition to a wider contact, unreleased stops also have a more fronted articulation. Figure (8) shows a comparison between an intervocalic and a wordfinal nasal in the words [mãn'] 'husband' and [õnī] 'that'. As for the stops, it can be seen that word final nasals have a wider and more fronted tongue contact. The same patterns of contact have been observed with the other speakers of the study.

(7) Palatograms and linguograms of the words [pat'] and [ota]
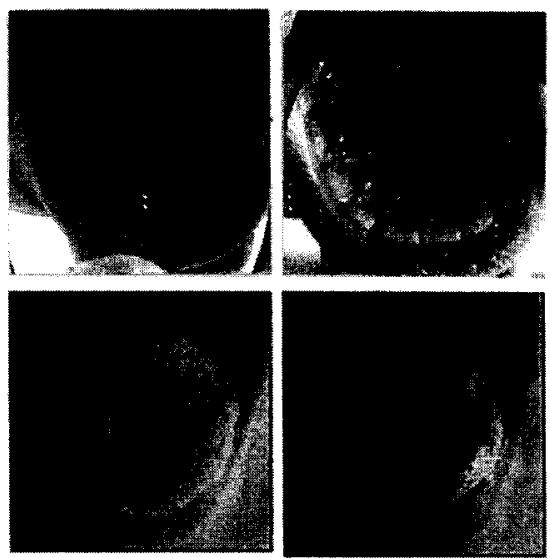

$\left[\mathrm{t}^{\mathrm{\prime}}\right]$

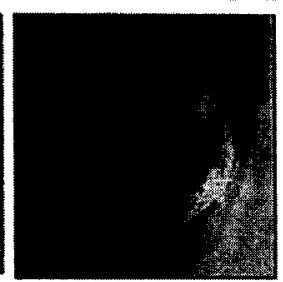

[t]
(8) Palatograms and linguograms of the words [mãn'] and [õñ]
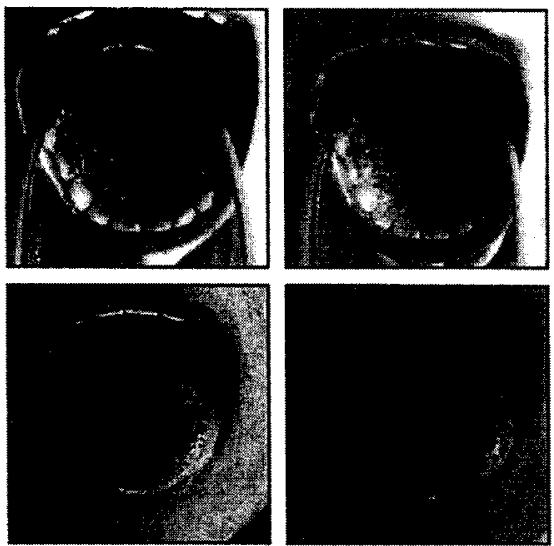

$\left[\mathbf{n}^{\top}\right]$

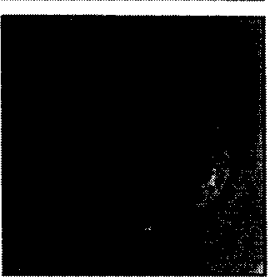

[n]

\subsubsection{Video}

Video data provide a good way to observe the behavior of labial consonants. Figure (9) compares lip closure during an intervocalic stop [p] in the word [opo] 'penis' and in a final [ $p^{\text {'] }}$ in the word [sop'] 'hair'. The image for the intervocalic [p] is taken $20 \mathrm{~ms}$ before lip opening, whereas the image of the final unreleased $\left[\mathrm{p}^{\top}\right]$ is taken $200 \mathrm{~ms}$ after lip closure. Comparison of the images suggests firmer closure with the final unreleased stop. This firmer closure accounts for the continuation of lip closure necessary to produce an unreleased stop. Figure (10) compares lip posture during an initial post-stopped nasal $\left[\mathrm{m}^{\mathrm{b}}\right]$ and an unreleased final nasal [ $\mathrm{m}$ '] in the word $\left[\mathrm{m}^{\mathrm{b}} \mathrm{e} \mathrm{m}^{\prime}\right]$ 'to enter'. The images are taken $20 \mathrm{~ms}$ before lip opening for $\left[\mathrm{m}^{\mathrm{b}}\right]$ and $200 \mathrm{~ms}$ after lip closure 
for $\left[\mathrm{m}^{\urcorner}\right]$. Examination of the images suggests a firmer closure with the final unreleased nasal.

(9) Lip closure during intervocalic

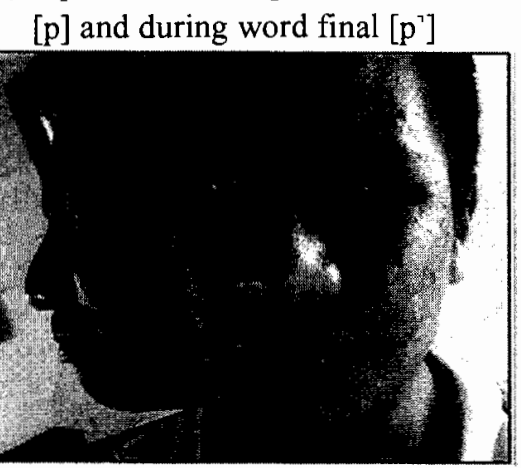

[p]

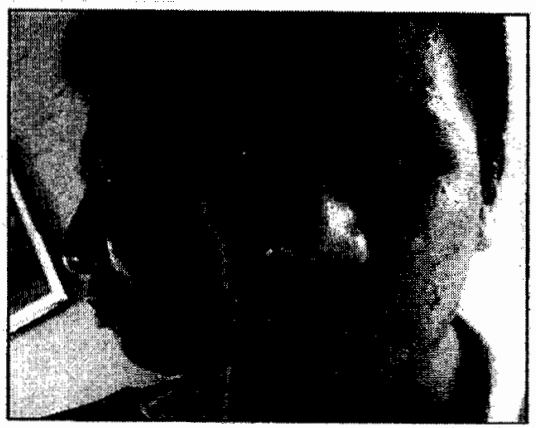

[p']
(10) Lip closure during intervocalic $\left[\mathrm{m}^{\mathrm{b}}\right]$ and during word final $\left[\mathrm{m}^{\mathrm{T}}\right]$

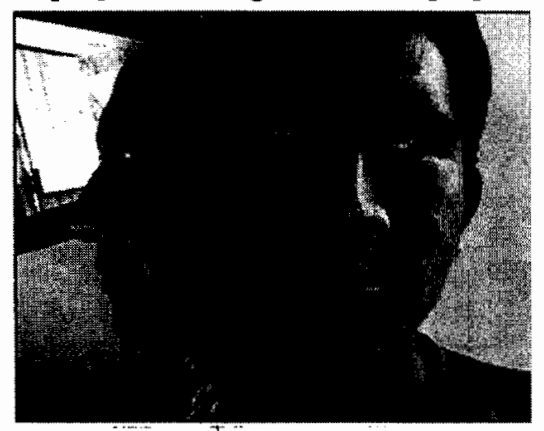

$\left[\mathrm{m}^{\mathrm{b}}\right]$

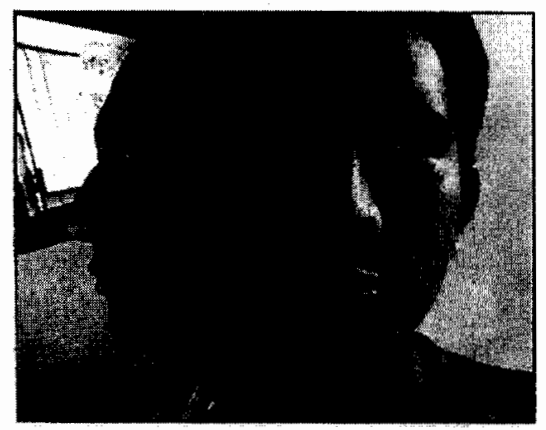

[m']

\section{Phonology}

When they are not followed by a pause or at the end of a sentence, unreleased stops become voiced if followed by a voiced segment. If a voiceless stop consonant follows, the unreleased stop is exploded. In a few cases it has been observed that an unreleased stop assimilates completely to the following voiceless consonant, which geminates. These cases are described in the following sections.

\subsection{Progressive Assimilation of a Nasal to Place Features of an Oral}

The examples given below in (12), (13) and (14) show examples of the assimilation of the nasal place features to the preceding oral. For example in (12), the word [?ednã] 'pregnant' is realized when the final unreleased stop [ $\left.\mathrm{t}^{\top}\right]$ assimilates to the voicing features of the following nasal when a suffix [nã] (adjectivizer) is added to the word [?et'] 'child'. This can be summarized by (11) 
which states that an unreleased voiceless stop becomes voiced when followed by a nasal.
(11) Voicing Rule
$\mathrm{C}^{2}[$-voice $]>\mathrm{C}[$ +voice $] / \_\mathrm{N}$

Note that two possible ways have been observed to produce what is interpreted as voicing assimilation for [ $\left.\mathrm{t}^{ }\right]$. In the first there is clear acoustic evidence of voicing whereas in the second voicing does not appear in the acoustic signal but voicing is perceived probably due to the short duration of the inter-segmental period.

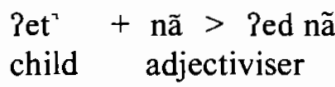

'pregnant'

lop' + nã > Robmã
hole $\quad$ adjectiviser
ãndik' + nã > andigyã
buttocks adjectiviser
'with buttocks'

'pierced'

\subsection{Vowel epenthesis}

Vowel epenthesis occurs between two adjacent underlying consonants in the following environments: 1) in underived environments; 2) lexically, between a root and an affix; 3) post-lexically, between two words inside a compound or clitic-host unit. The quality of the epenthetic vowel is the same as that of the preceding underlying vowel.

(15) Epenthesis Rule

$\emptyset \rightarrow V_{1} / V_{1} C_{-} C$

(16) Examples of epenthesis in environment 1

$\begin{array}{llll}/ \mathrm{kirk} / & \rightarrow & {\left[\mathrm{kirik}^{\prime}\right]} & \text { 'mosquito' } \\ / \mathrm{pikp} / & \rightarrow & {\left[\mathrm{pikip}^{\prime}\right]} & \text { 'tree bark' } \\ / \text { ept/ } & \rightarrow & {\left[\mathrm{e \beta et}^{\prime}\right]} & \text { 'thin' }\end{array}$

(17) Examples of epenthesis in environment 2
bik + pa
$\rightarrow$
bi.ki.pa
'seat, bench'
to sit nominalizer
pi.hop + pa $\rightarrow$ pi.hopo.pa 'drier'
to dry nominalizer
ko:kot $+\mathrm{pa} \quad \rightarrow \quad$ ko:kotopa 'bridge'
to pass nominalizer 
In post-lexical epenthesis, we have one additional condition in the environment of the rule - the epenthetic vowel must separate a stress clash.

$$
\emptyset \rightarrow \mathrm{V} / \mathrm{V} . \mathrm{C} \_\mathrm{CV}
$$

(19) Examples of post-lexical epenthesis in environment 3

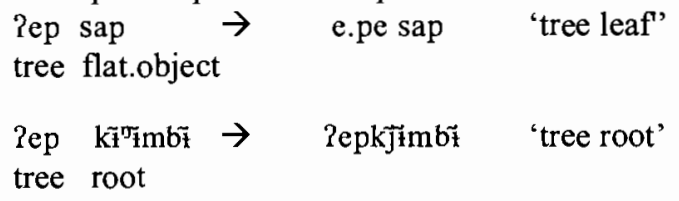

Note that epenthesis occurs lexically in ko:kotopa, but not post-lexically in ?epk $\tilde{\mathrm{ju}} \mathrm{mb \tilde {i }}$, although, in both cases, no stress clash takes place.

In a few cases it has been observed that an unreleased stop assimilates completely to the following consonant, which geminates. Such an example is given in (20).

(20) Karitiana haadna pip ${ }^{\top} t \int a{ }^{\top}$ '...morder 'In Karitiana $t f a k^{\prime}$ ' is to bite'

$$
\text { [...pitf:ak'...\#] }
$$

\section{Syllable structure}

One important thing to note is that when assimilation or epenthesis takes place, resyllabification take place too. This is because in this language a non-nasal in root-final position triggers epenthesis whereas a nasal does not, as shown in (21) and (22) (see Storto (1999) for more details on prohibited codas and obligatory onsets).

$$
\begin{aligned}
& \text { bik }+ \text { pa } \rightarrow \text { bi.ki.pa } \rightarrow \text { 'seat, bench' } \\
& \text { to sit nominalizer }
\end{aligned}
$$

$$
\begin{aligned}
& \text { hõ.rõn }+\mathrm{pa} \rightarrow \text { hõ.rõn.pa 'basin' } \\
& \text { to wash nominalizer }
\end{aligned}
$$

\section{Conclusion}

In this paper it has been shown that unreleased stops are identified by formant transitions and that these consonants are produced by sustaining the stop closure for a longer period compared to an exploded stop. This affects pharyngeal pressure, which decreases gradually. In the case of nasals, nasal airflow perseveres longer for final nasals than for initial or intervocalic nasals. The tongue contact is wider and more fronted for unreleased stops and nasals. In context, 
unreleased stops assimilate or are exploded and resyllabify as the onset of the following syllable.

\section{Acknowledgments}

We wish to thank Luiz Karitiana, Nelson Karitiana, Ignacio Karitiana, and João Karitiana for their patience and their collaboration during the experiments. Our colleagues of the Tupi comparative project contributed to fruitful discussions on various aspects of this work. Data were collected during several fieldwork trips in Brazil.

Part of this research has been supported by the Wenner-Gren Foundation, by the ARC convention 98-02 $n^{\circ} 226$ of the Belgian Ministry of Scientific Research, and by two Brazilian research funding agencies: FAPESP (Post-Doctoral grant 01/00172-9) and CNPq (PROFIX grant 540532/01-0 NV).

\section{References}

Cook, T.L. 1969. Efik. In E. Dunstan (ed.) Twelve Nigerian Languages, 35-46. London: Longmans Green.

Dart, S. 1999. Articulatory and acoustic properties of apical and laminal articulations. UCLA Working Papers in Phonetics, 79. University of California Los Angeles.

Gabas Junior, N. 1998. Estudo fonologico da lingua Karo. Munich: Lincom Europa.

Gabas Junior, N. 1999. A Grammar of Karo, Tupi (Brazil). PhD Dissertation, University of California, Santa Barbara.

Galucio, A.V. 1994, Fonologica segmental da lingua Mekens. IX Encontro Nacional da ANPOLL. Caxambu, MG. Anais do IX Encontro Nacional da ANPOLL, Vol. 1. 988-998.

Galucio, A.V. 1996. Mekens phonology. Ms. University of Chicago.

Ladefoged, P. \& I. Maddieson. 1996. The Sounds of the World's Languages. Oxford: Blackwell.

Laver, J. 1994. Principles of Phonetics. Cambridge: Cambridge University Press.

Moore, D.A. 1984. Syntax of the language of the Gavião indians of Rondonia, Brazil. PhD Dissertation, City University of New York.

Picanço, G. 1999. Estudo preliminar da fonologia da lingua Munduruku. Senior thesis, Universitade Federal do Para, Belém.

Rose, F. 2000. Elements de phonétique, phonologie et morphophonologie de l'Emerillon (Teko). Mémoire de DEA de Sciences du Langage. Université de Lyon II.

Storto, L. 1999. Aspects of Karitiana Grammar. PhD dissertation, MIT. 
Storto, L. \& D. Demolin 2002. Control and timing of articulatory gestures in preand post-oralized nasals in Karitiana. Paper presented at the $8^{\text {th }}$ Conference of Laboratory Phonology, Haskins Laboratories, Yale University, June 27-30.

Westermann, D. \& M.A. Bryan 1952. Handbook of African languages, Part II, Languages of West Africa. London: Oxford University Press.

Luciana Storto

MAE, Universidade de São Paulo

Av. Prof. Almeida Prado, 1466

CEP 05508-900 São Paulo, Brazil

luciana_storto@yahoo.com

Didier Demolin

ULB, Phonology lab., CP 175

50 av. F. Roosevelt

1050 Brussels, Belgium

ddemoli@ulb.ac.be 